\title{
A Study of Female Spouses of Male Alcohol Dependence Patients"
}

\author{
Dr. B. Shanthi ${ }^{1}$,Dr. K. Veeramuthu, M.D., D.P.M. ${ }^{2}$ \\ ${ }^{1,2}$ Madras Medical College. Chennai.
}

\section{Introduction}

The use of alcohol has been present since time immemorial. The problem of alcoholism is not just related to the alcoholics but also the lives of those around them are adversely affected especially the wives leading onto social, ccupational and psychological damage (24). Alcohol dependence is a complex behavior with far reaching harmful effects on the work, family and society. The most negatively affected are the spouse and children of an alcoholic. However less attention has been focused on them so far (25). There are a considerable number of anecdotal reports and research findings that suggest that individuals who are married to alcoholics have poor physical and mental health (4). The wives are too close to the problem and don't see how they are enabling the user. Two models have dominated the literature on alcoholism and marriage.

- $\quad$ Personality profile of the wives.

- Behaviour of them in reaction to their husband'sdrinking.

These wives suffer from various stressors due to their husband's alcohol dependence. They seek assistance to cope with the impact of the husband's drinking (34). This study is an attempt to study certain aspects of the wives of the alcoholic's mental health and compare them with the normal population. The wives of the alcoholics are an 'Unknown Universe' in Indian Society. Clinical work and some research suggest that partner responses to drinking may either facilitate or hinder treatment acceptance and recovery efforts (29). Hence the reason for taking up this study is justified.

\section{Review Of Literature}

Alcoholism

The term alcoholism is a widely used term first coined by Magnus Hass in 1849 but in medicine is replaced by alcohol dependence. Alcohol dependence is defined as a cluster of physiological, behavioural, and cognitive phenomena in which the use of a substance or class of substances takes on a much higher priority for a given individual than other behaviors that once had greater value (ICD-10). The impact of alcoholism on marital family functioning and the influence of marital family relationship on the development and maintenance of alcoholism are challenging problems. There are many areas where research has been carried out. One such area is the study of spouses of male alcoholics.

\section{Of Alcoholics}

Very often the wives of alcoholics have to perform the roles of both parents and may become physically or mentally ill (Berger, 1993). Female partners of male alcoholics have been labeled as 'enablers' or 'codependents'.'Codependency' is an unconscious addiction to another person's abnormal behavior.

An 'enabler' is a person who unknowlingly helps the alcoholic by denying the drinking problem exists and helping the alcoholic to get out of troubles caused by his drinking (Silverstein, 1990).

\section{Personality}

Allport defines personality as the 'dynamic organizations within the individual of those psychophysical systems that determine his unique adjustments to his environment'.

\section{Effect of alcoholism on the wives}

There is a need to understand and explain the emotional problems of wives of alcoholics apart from their disturbed personality model and coping behavior, but this is still lacking. 
Lewis et al. (1937) (33) said that the wives of alcohol dependent individuals found an outlet for aggressive impulses in their marital relationship.

In the 1950 's, the 'stress model' was proposed. It stated that the wive's pathological behavior was an attempt to resolve the alcoholic crisis and to return the family to the previous stability.

Whalen et al. (1953) (54) placed wives of alcohol dependent individuals into four categories,

- $\quad$ Suffering Susan - wife who has masochistic trends.

- Controlling Catherine - wife who needs control

- Wavering winnifriend - wife who struggles with ambivalence

- Punitive Polly - wife who conflicts with aggression.

Futterman et al. (1953) (17) called the 'disturbed personality model' the central theme stating that alcoholism in the husband is caused by the psychopathology of non alcoholic spouses.

Sangy, D.de et al. (1964) (42) studied the personality of wives of alcohol dependent individuals. They took 100 couples and a clinical interview was conducted. No psychological tools were used. The results showed that the wives were dominant from the beginning of the marriage. There were common traits like dependency, neuroticism and frigidity. Rae and Forbes et al.(1966) (38) in their study of a sample of 26 wives of alcohol dependent individuals using MMPI found an elevation of psychopathic deviance scale. They postulated that the spouses' personality is as important as that of the patient in mainly subsequent abstinence.

Then emerged the 'Psychosocial model'. It concluded that a broad variety of variables including personality and situational factors are important (Tayler and Schaffee, 1979).

Edwards, Harvey and whitehead et al. (1973)(15) in their study concluded that these wives are women who have essentially normal personalities of different types, rather than any one particular type. They may suffer personality dysfunction.

Orford et al.(1976) (37) used Eyesenck personality Inventory on 100 wives of alcoholics and found raised neurotism scores in them.

Tomilleri, Herjanic, Wetbel et al. (1977) (50) studied the personality of the wives of alcoholics together with certain other aspects like.

- $\quad$ Psychiatric diagnosis in wife

- $\quad$ Family history of psychiatric disturbances

- $\quad$ Type of marriage.

The tools used were the CPI (Gough, 1959) - California personality inventory and SSIAM (Structured scaled Instrument to assess maladjustment) Rothberg et al. (1986) (40) articulates the notion that problem drinkers and their partners develop complimentary relationships in which each reinforces the pathological needs of the other.Asher and Brisett et al. (1988) (2) emphasise on codependent behaviors. Maristo, et al., (1988) reported both intrapsychic and situational determinants of alcoholism.

Avila Escribano and Ledesma Temeno et al. (1990) (2) studied personality characteristics of wives of Spanish alcohol patients through a structured interview and the MMPI.T.S.S. Rao et al. (1991) (51) conducted a study on 30 wives of alcoholics assessing the personality characteristics using EPI and 16 PF. These alcoholics satisfied Feighner's criteria and the wives were compared with the wives of 30 normal controls matched on marital and socio demographic variables. The results showed that there were no statistically significant difference between the two groups on EPI and scores were within normal limits. Both the groups had a similar score on $16 \mathrm{PF}$ being submissive, timid, conventional, conservative, dependent and poised. These were not in favour of the concept of 'pathological wives' causing alcoholism in their husbands as advocated by some of the western studies.

Suman and Nagalakshmi et al. (1993)(49) studied the personality dimensions of alcohol dependent individual's spouses and administered EPQ to them. The results showed that these spouses were less extroverted than normal wives who were more sociable, carefree and relaxed ininterpersonal relationships. They were more inhibited, more withdrawn and less assertive in interpersonal relationships (Kodandaram 1997).Grubi, et al., (1998) (19)used the EPQ an 100 wives of alcoholics and studied their personality dimensions in comparison to 100 wives of non-alcoholics. They compared these two groups according to psychiatric treatment frequency. EPQ was used to measure the main personality dimensions.

A structured psychiatric interview and self assessment of behavior before marriage was used. The result showed that these wives were less extraverted than the control group. They didn't differ in 2 other main personality dimensions - neurotism and psychotism. There were psychiatric treatments more often during their marriage than the wives of non alcoholics.. The control group had few psychiatric treatments during the marriage than before the marriage. 
Kodandaram et al. (1997) (31) studied the personality profiles of wives of alcohol dependent individuals and compared it with the wives of non alcoholics. The sample size was 30 vs 30 . They completed the General Health Questionnaire and 16 PF form C. The wives of Alcohol dependent Individuals differed significantly from the control group. They were glum, silent, timid, eccentric and were group dependent and had lack of will control and displayed somatic anxiety.The family has increasingly been recognized as an important component in the development, maintenance and treatment of Alcoholism. Few empirical studies have however examined alcoholism in a family context (The American Journal of Drugs and addition abuse 1993, vol.19, No.l).Subsequent reviews cite further research supporting the stress model and refuting the disturbed personality model. (Finney, Moos, Cronkite and Gamble, 1983, Cramberg 1989; Bush and Wilson 1994; 'O' Farrell, Harrison and Cutter 1981).

\section{Coping behavior of the wives of alcoholics}

Coping is a process of managing taxing circumstances expending effort to solve personal and interpersonal problems and seeking to master, minimize or reduce stress or conflict (Lazarus: R. 1984).The nature of coping behavior of them depends on the personality, degree of duration of her husband's alcoholism and duration of marriage.Jones A. Jackson et al. (1954) (27) first propounded the 'stress model'. She conceived the behavior of alcoholic's wives in terms of crisis reaction precipitated by the stress posed by their husband's drinking. She outlined 9 stages of family adjustment to the problem. They were seen as neurotic and poor copers who were obsessed with controlling their husband's alcohol drinking (Kalashian, 1959).James and Goldman et al. (1971) (28) have reported a study which reports that the wives of alcoholics used all sorts of coping in response to the intensity of the alcoholismic episode.Cheek, et al. (1971) (13) trained the wives of alcoholics to use behavior modification techniques in order to change family interaction. She found that people who participated in the training reported atleast moderate improvement in marital communication.Orford and Guthrie's (1976) (37) factor analysis of the response of the wives of alcoholics to 50 yielded five distinct styles of coping behavior namely Avoidance, Withdrawal, and Protecting alcoholic husband.T.S.S. Rao and Kuruvilla et al. (1992) (43)conducted a study on 30 wives of alcoholics using a Orford - Guthrie - 'Coping with drinking questionnaire'. The commonest coping behavior reported was discord, avoidance, indulgence and fearful withdrawal while marital breakdown, taking special action, assertion and sexual withdrawal were least frequently used.

T.S.S. Rao et al. (1998) did a study on 100 wives of alcoholics using 'CWDQ' again. The result showed that avoidance was the commonly endorsed coping behavior. There was a significant correlation between all the coping components and alcohol related problems. No correlation was observed between neurotism scores and coping behavior. They concluded that both personality and situational variables play a role in determining the coping behavior of the wives of alcoholics.C. Ramasubramanian et al. (1998) attempted to describe the different coping styles adopted by wives of alcoholics who were attending TRISHUL, a De-addiction Hospital, Madurai and whether or not they differ with other wives who did not have an alcoholic husband.Forty wives accompanying their alcoholic husbands to De-addiction hospital were selected randomly and their coping styles (usingcoping behavior questionnaire) were collected. Another 40 wives whose husbands were neither alcoholic nor suffering from any medical illness were randomly selected and matched with the former group. The author found that there exists a significant difference between the groups in different styles of copingR Chandrasekaran, V Chitralekha et al. (1998) studied 100 wives of alcoholics with a confirmed diagnosis of alcohol dependence syndrome were studied with a 'Coping with drinking questionnaire'. "Avoidance" was the most commonly used coping behavior. There was a significant correlation between all the coping components and alcohol related problems. No correlation was observed between Neurotism scores and coping behavior. It was evident that both personality and situational variables play a role in determining the coping behavior of the wives of alcoholics.

Wives with active alcoholic partners have been found to experience a higher level of depression, trauma and stress related disorders. (Roberts and Brent, 1982, Svenson Foster, Woodhead, and Platt, 1995). The Wives of 75 alcohol dependent individuals, admitted in the De-addiction centre at NIMHANS were selected and 'coping with drinking questionnaire' was admitted. The major coping styles used were Avoidance (53\%), Discord (57.5\%), Fearful Withdrawal (40.4\%) and Sexual Withdrawal (25.8\%) (M. Sreedevi, Gangadaraiah and V. Benegal, Bangalore, UP, Apr 2001).

\section{Depression in the wives of alcoholics}

Alcoholism in addition to the alcohol dependent individual affects the other family members also with just the same intensity if not more.

Wives of alcoholics have an incredibly difficult time. It is she who has to live with him, day in, day out. 
The wives of alcoholics face immense problems. The uncertainty of his behavior, poor communication, social embarrassment, fear of the

future, frustration at not being able to alter his drinking and having to take over his responsibilities in addition to her own puts her under a lot of stress both physically and psychologically (Selwyn Stanley 2004). They have to endure years of isolation, blame of relatives, lack of friends, violence and unsatisfactory sexual relations (Wiseman, J. 1991).

They involve in fewer social activities and report more stressful life events and suffer from elevated rates of depression and anxiety and somatic complaints.Few studies speak of the psychopathology of the non alcoholic spouse married to an alcoholic and of her tendency to breakdown or decompensate if his deviance diminishes (McDonald, 1956).Wiseman, Jacqueline et al. (1975) describe the self reported lives of 75 women married to the alcoholics out of them $40 \%$ got separated from the husbands while others tried to help them. If the husband of such a wife attempted to stop drinking after this separation occurred, his wife might be placed under stress by the choice they used. Orford et al. (1976) stated that the function normally carried out by the husband have to be taken over by the wife will add to her psychological stress.Crisp and Barber et al. (1995) studied about the hardship experienced by the wives of alcoholics. He used the drinkers partners distress scale to measure depression.

Wives with active alcoholic partners have been found to experience a higher level of depression* trauma and stress related disorders. (Roberts and Brent, 1982, Svenson Foster, Woodhead, and Platt, 1995).

Rosamma Varghese, Sekar et al. (1998) examined the psychological distress, social disability and coping patterns in wives of alcoholics. They observed that most of them were moderately distressed, suffered mild degree of overall disability. The frequently used coping patterns were discord, avoidance, assertion, fearful withdrawal and marital breakdown. The working women experienced higher degrees of psychological distress and social disability compared to non-working women. Shantala, M.M.George, J.Henry and V.Benegal et al. Bangalore (2001) Studied the stress and morbidity in spouse of male alcoholics in a sample of 100 wives of alcohol dependent patients seen at the De-addiction Unit, NIMHANS, Bangalore. Instrument used was semi-structured questionnaire, incorporating the mood disorders and to tap stressors. The result showed that the common stressor faced by the spouse was their husbands drinking, financial problems and physical abuse. Comorbidity seen commonly were depressive disorder, somatization disorder and generalized anxiety disorder. (Journal of studies on Alcohol and drugs, Vol 68, 2007, Issue 1: Jan 2007) Deborah A. Dawson, Bridget F. Grant, S. Patricia Chou, Fredrick S. Stinson studied the impact of partner alcohol problems on womens' physical and mental health. This was a retrospective survey of a nationality representative sample of U.S consisting of 11,683 married women. Classification of their own alcohol use disorders were based on DSM IV criteria. Mental health measures included DSM IV mood and anxiety disorders, number of past year stressors and SF 12v2 based psychological quality of life. Results showed what women with alcoholic partners were more likely to experience mood disorders and anxiety disorders. They had lower psychological quality of life scores.

\section{Suicide in the wives of alcoholics}

Adjustment to an alcohol problem of husband may result in an increase in the family's emotional and physical illness (Bloom, 1985) and altered family function. The spouses suffer from elevated rates of depression and anxiety (Halford et al., 1999).

The wives of alcoholics usually resort to suicidal behavior in response to the stress associated with their husband's drinking.

However there are not many studies throwing light on the suicidal attempts and the intent behind the attempt.

\section{Suicide is an attempt to end the pain, not the life.}

This study brings to light the vulnerability of the wives of alcoholics to various psychosocial stressors and the need to screen them and include them in the treatment endeavours.

The efforts to understand and treat alcohol dependence will be more productive if partner behaviours are incorporated into assessment and intervention procedures. (Rob J Rotunda, Laurawest, Timothy J o' Farell 2004).

1. To assess the personality profile of the wives of alcohol dependence patients.

To study their coping behavior.

2. To evaluate the presence of depression in them.

3. To evaluate the suicidal intent in them.

4. To compare the above factors above with those of controls. 


\section{Hypothesis}

1. There is no difference in the socio-demographic profile between the wives of alcohol dependence patients and the controls.

2. There is no difference in the personality profile between the wives of alcohol dependence patients and the controls.

3. There is no difference between the coping behaviors of the wives of alcohol dependence patients and the controls.

4. There is no depression in the wives of alcohol dependence patients than the controls.

5. There is less suicidal intent in the wives of alcohol dependence patients than the controls.

\section{Design of the study}

\section{Methodology}

Case control study Setting The study was conducted over a period of three months from May 2010 to October 2010 in the de-addiction clinic and de-addiction ward of Institute of mental Health, Chennai.

Subjects The subjects of this study were the wives of alcohol dependence patients attending the de-addiction clinic and in the de-addiction ward of Institute of Mental Health and meeting the inclusion and exclusion criteria.

Cases

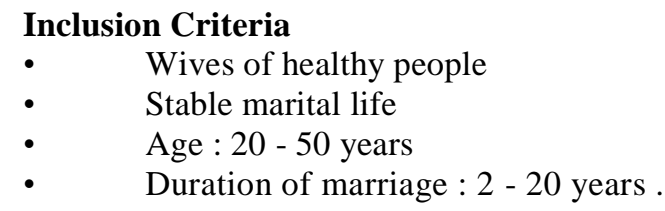

\section{Exclusion Criteria}

- $\quad$ Presence of substance abuse

- $\quad$ Presence of Axis I/II disorders

- $\quad$ Presence of medical illnesses

\section{Methods}

The study was discussed and approved by the Ethics committee of the research panel of the Madras Medical College Chennai. The cases were the wives of the male patients diagnosed as alcohol dependence syndrome in the de-addiction clinic and ward of IMH. They were diagnosed using the ICD-10 Criteria for alcohol dependence and were selected from 50 consecutive patients. Some preferred outpatient treatment and some preferred inpatient treatment. Finally a sample of 30 patients constituted the study group. The diagnosis was made by the medical officer in charge and confirmed by a consultant after carefully ruling out psychotic disorders. Informed consent was obtained from them. The control groups were the wives of healthy individuals. A group of 30 people constituted the control group. Each case was matched to the control on socio demographic variables. The following instruments wereadministered and scoring done under the supervision of 2 independent qualified psychiatrists.

\section{Materials Used}

- A semi structured proforma for Socio-demographic data.

- 16 PF questionnaire - Form E (catell 1970).

- Hamilton depression rating scale (Hamilton)

- Brief cope (carver)

- Beck suicide intent scale (Beck AT)

A semi structured proforma for socio- demographic data was used to collect the details regarding age, education, occupation, religion, type of family, family materials history of alcohol dependence. The sixteen personality factor questionnaire (catell) The sixteen personality factor questionnaire was developed by catell and is an objectively scorable test devised by basic research. If gives a most complete coverage of personality in a brief time The form $\mathrm{E}$ of the $16 \mathrm{PF}$ was used for the study as it was found that most of the subjects had only minimal formal education. As they were not very proficient in English a Tamil translated version was 
given to them. The $16 \mathrm{PF}$ list was individually administered to them which took 45-60 minutes to complete. The same was repeated with controls.

Personality is measured based upon 16 independent dimensions. Apart from these, it also measures 8 secondary dimensions of which the first four are of most interest in clinical research.

These dimensions reflect the key characteristics of human personality.

There is a raw score from 1 to 10 for each factor which are inturn converted to a 'standard ten (sten) score' from through 10. The sten scores of 4 through 7 are considered to average.

The Primary Traits Covered By The 16 Pf Test

\begin{tabular}{|c|c|c|}
\hline Factor & Low Stem Score Description & High Stem score description \\
\hline $\mathbf{A}$ & Cool, $\quad$ reserved, impersonal, & Warm, outgoing, kindly, easygoing, \\
\hline $\mathbf{B}$ & Concrete thinking, less intelligent & $\begin{array}{l}\text { Abstract thinking, more intelligent, } \\
\text { bright. }\end{array}$ \\
\hline $\mathbf{C}$ & $\begin{array}{l}\text { Affected by feelings, emotionally } \\
\text { less stable, annoyed. }\end{array}$ & Emotionally stable, mature, faces reality \\
\hline $\mathbf{E}$ & $\begin{array}{l}\text { Submissive, humble, mild, easily } \\
\text { led, accommodating. }\end{array}$ & $\begin{array}{l}\text { Dominant, assertive, aggressive, } \\
\text { stubborn. }\end{array}$ \\
\hline $\mathbf{F}$ & Sober, restrained, prudent, serious & $\begin{array}{l}\text { Enthusiastic, spontaneous, heedless, } \\
\text { expressive, cheerful. }\end{array}$ \\
\hline $\mathbf{G}$ & $\begin{array}{l}\text { Expedient, disregards rules, } \\
\text { self indulgent. }\end{array}$ & $\begin{array}{l}\text { ConscientiouSjConforming, moralistic, } \\
\text { rule-bound }\end{array}$ \\
\hline $\mathbf{H}$ & Shy, threat sensitive, timid. & Bold, venturesome, uninhibited. \\
\hline $\mathbf{I}$ & $\begin{array}{l}\text { Tough minded, self reliant, rough, } \\
\text { realistic. }\end{array}$ & $\begin{array}{l}\text { Tender minded, sensitive, over } \\
\text { protected. }\end{array}$ \\
\hline $\mathbf{L}$ & $\begin{array}{l}\text { Trusting, accepting condition, easy } \\
\text { to get on with. }\end{array}$ & \begin{tabular}{|lll}
$\begin{array}{l}\text { Suspicious, hard } \\
\text { distrustful, skeptical }\end{array}$ & to fool, \\
\end{tabular} \\
\hline $\mathbf{M}$ & $\begin{array}{l}\text { Practical, careful,steady, } \\
\text { conventional. }\end{array}$ & Imaginative, $\quad$ absent $\quad$ minded \\
\hline $\mathbf{N}$ & $\begin{array}{l}\text { Forthright, unpretentious, open, } \\
\text { genuine, artless. }\end{array}$ & $\begin{array}{l}\text { Shrewd, polished, socially aware, } \\
\text { diplomatic. }\end{array}$ \\
\hline $\mathrm{O}$ & $\begin{array}{l}\text { Self assured, secure, feels free of } \\
\text { guilt, untroubled, self satisfied. }\end{array}$ & $\begin{array}{l}\text { Apprehensive, self blaming, guilt prone, } \\
\text { insecure, worrying. }\end{array}$ \\
\hline Ql & $\begin{array}{l}\text { Conservative, respecting traditional } \\
\text { ideas }\end{array}$ & $\begin{array}{l}\text { Experimenting, liberal, critical, open } \\
\text { to change }\end{array}$ \\
\hline Q2 & Group oriented, listens to others. & $\begin{array}{l}\text { Self sufficient, resourceful, prefers own } \\
\text { decisions. }\end{array}$ \\
\hline Q3 & Lax, careless of social rules. & Socially precise, compulsive. \\
\hline Q4 & Tranquil, composed, unfrustated. & Frustrated, overwrought, has high drive. \\
\hline
\end{tabular}

\section{Hamilton Rating scale for depression}

The Hamilton rating scale for Depression (HAM-D), developed by M Hamilton in the 1960 is the most widely used rating scale to assess symptoms of depression. It is an observer - rated scale consisting of items that evaluates depressed mood, vegetative and cognitive symptoms of depression and co- morbid anxiety symptoms. The clinician rates the symptoms on a 4 point scale.

It is the usual standard against which other depression rating scales are validated. The strengths of the HAM-D include its excellent validation / research base and ease of administration. Its use is limited in individuals who have psychiatric disorders other than primary depression. The Interrater reliability for the total score ranges from 0.87 to 0.95 . validity of the scale appears high.

The scoring is as follows: 0-19 - no depression 20-30 - mild depression 31-40 - moderate depression $>40 \quad-\quad$ severe depression

\section{Brief Cope}

The brief cope is the abridged version of the COPE inventory and presents 14 scales all assessing different coping dimensions. It is built from acknowledged theoretical models. It can be used to assess trait coping and state coping i.e. the usual way people cope with stress in everyday life and the particular way people cope with a specific stressful situation respectively.

Brief cope is used for many health relevant studies and is translated in many languages. It is an easy to use coping measure used worldwide. Functional coping strategies are linked to good self esteem and lower psychological distress and less functional strategies to poor self esteem and high psychological distress. 


\section{There are certain desirable and undesirable coping behaviours.}

Carver (1997) - 28 items - 14 subscales. Each item is rated on a 4 point scale.

1. I haven't been doing this at all.

2. I have been doing this a little bit.

3. I have been doing this a medium amount.

4. I have been doing this a lot.

Scales are computed as follows. No reversals of (Higher scores better coping capacity). The tamil version was used for the patients. Each domain has 4 responses.

\section{Desirable coping Subscaies}

- Self Distraction

- $\quad$ Active Coping

- Use of emotional support

- Use of Instrumental support

- Venting

- Positive Refraining

- Planning

- Humour

- Acceptance

- Religion

\section{Undesirable coping subscaies}

- Denial

- $\quad$ Substance Use

- Behaivoural disengagement

- $\quad$ Self Blame

\section{Items}

1,19

2,7

$\mathbf{5 , 5}$

10,23

9,21

12,17

14,25

18,28

20,24

22,27

Items

$3,84,116,1613,26$

Reliability for all subscales exceeds 0.60 except venting 0.50 , denial $=0.54 \&$ acceptance $=0.57$

\section{Beck Suicide Intent Scale}

This scale was developed by Aaron. T. beck and his colleagues at the University of Pennsylvania for use with patients who attempt suicide but survive. To understand the severity of the suicide attempt it is important to understand patients will to die.

It has 15 items with 3 sub items in it and 0-8 are rated by the interviewer and from 0-15 are by self report. The

\section{last responses in each item are most indicative of severe suicide intent.}

The scoring is as follows. 15-19 low intent

20-28 medium intent

$29+$ high intent. 


\section{Statistical Analysis}

Data was analysed using invariate techniques, chi-square test for categorical variables and -test for continuous variables.

To found out the correlation pearson product moment correlation was used. Analysis was done using with the help of a statistician and using SPSS-14 version.

\section{Results And Observations}

Table 1

COMPARISON OF MEAN AGE OF THE TWO GROUPS

\begin{tabular}{|l|l|l|c|}
\hline Subjects & N & Mean & p value \\
\hline Cases & 30 & 30.97 & 0.62 \\
\hline Controls & 30 & 30.07 & \\
\hline
\end{tabular}

Table 1 and Fig. 1 show the mean age of the two groups. It is evident that the mean age of the cases is 30.97 and the mean age of the controls 30.07 . There is no significant statistical difference between the mean age of the two groups.

Figure 1 comparison Of Mean Age Of The Two Groups

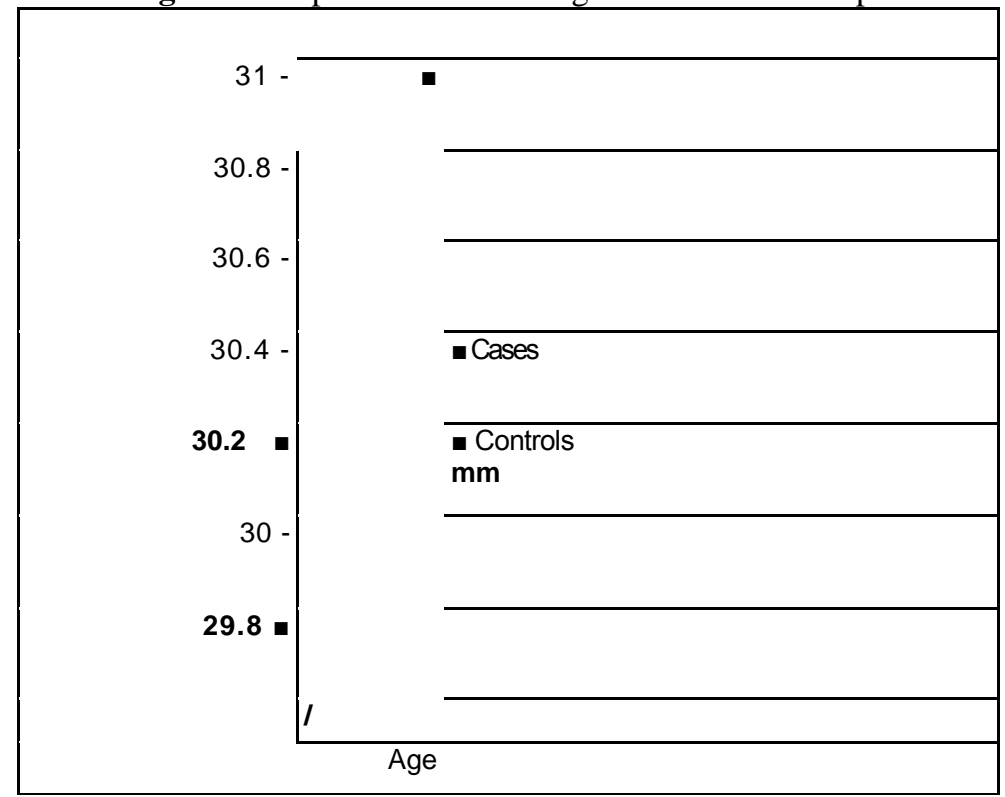

Table 2 Comparison Of Educational Status Of The Two Groups

\begin{tabular}{|l|c|c|c|l|}
\hline Education & Cases & Controls & Chi-Square & p value \\
\hline Illiterate & 2 & $\mathbf{3}$ & \multirow{2}{*}{$\mathbf{0 . 9 0 1}$} & \multirow{2}{*}{0.924} \\
\cline { 1 - 3 } Primary & 7 & $\mathbf{9}$ & \\
\cline { 1 - 3 } Secondary & 18 & $\mathbf{1 6}$ & \\
\cline { 1 - 3 } Degree & 2 & $\mathbf{1}$ & \\
\cline { 1 - 3 } Professional & 1 & $\mathbf{1}$ & & \\
\hline
\end{tabular}

Table 2 and figure 2 describes the educational status of the two groups. Among the cases group 2 were illiterate, 7 had primary education and 18 had secondary education, 2 had completed a degree course and 1 was a professional. Among the control group 3 were illiterate,

9 had primary education-16 had secondary education, 1 had completed a degree course and 1 was a professional. There is no significant statistical difference between the two groups in educational status. 
Figure 2 Comparison Of Educational Status Of The Two Groups

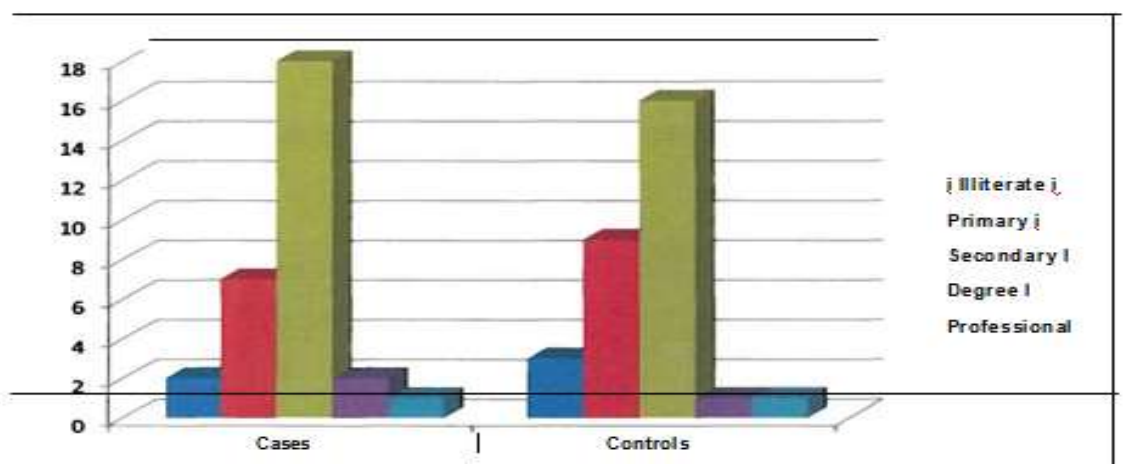

Table 3 Comparison Of Occupation Of The Two Groups

\begin{tabular}{|l|l|c|c|l|}
\hline Occupation & \multicolumn{1}{|c|}{ Cases } & Controls & Chi-Square & p value \\
\hline Unemployed & 15. & 12 & 0.667 & 0.881 \\
\cline { 1 - 2 } Unskilled & 12 & 15 & \\
\cline { 1 - 2 } Skilled & 2 & 2 & & \\
\hline Professional & 1 & 1 & & \\
\hline
\end{tabular}

Table 3 and figure 3 describe the occupation of the two groups. Among the cases group 15 were unemployed 12 were involved in unskilled work and 2 were employed in skilled work, 1 was a professional. Among the control group 12 were unemployed, 15 did unskilled job and 2 were involved in skilled work and 1 was a professional.From the $\mathrm{p}$ value it is evident that there is no significant statistical difference between the two groups in occupation.

Figure 3 Comparison Of Occupation Of The Two Groups

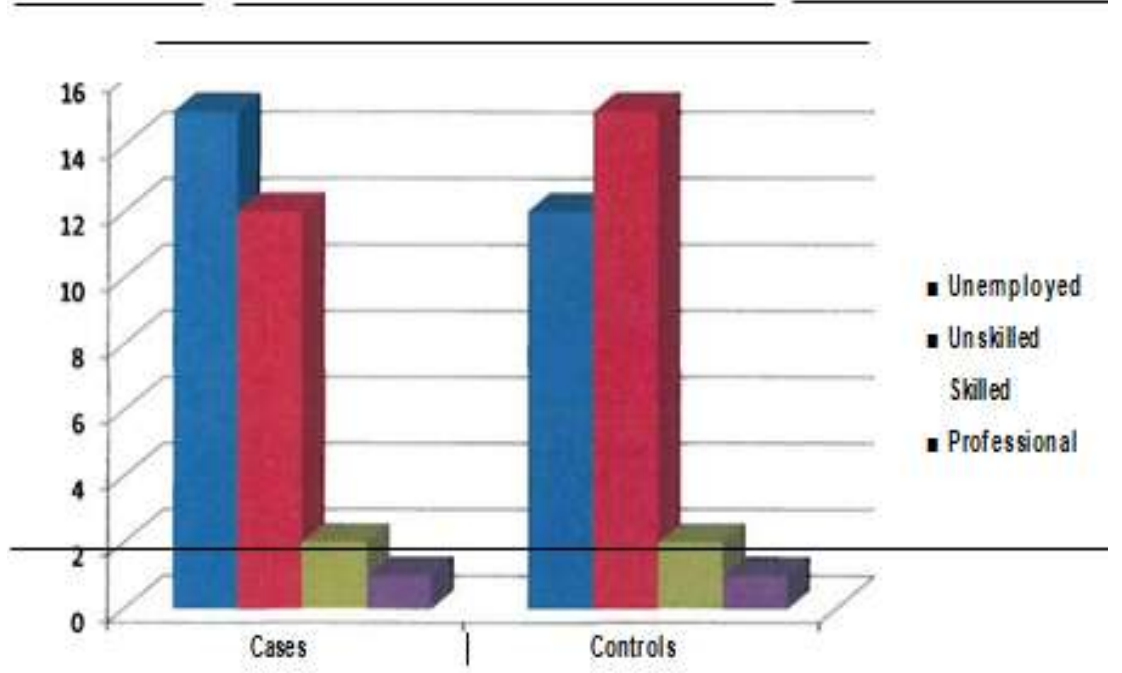

Table 4 Comparison Of Family History Of Alcohol Defendence Of The Two Groups

\begin{tabular}{|l|c|c|c|l|}
\hline Family H/o & Cases & Controls & Chi-Square & p value \\
\cline { 1 - 3 } Present & 20 & $\mathbf{2 3}$ & 0.739 & 0.390 \\
\cline { 1 - 3 } Absent & 10 & $\mathbf{7}$ & & \\
\hline
\end{tabular}

Table 4 and figure 4 describe the family history of alcohol dependence of the two groups. Among the case group 20 had a family history of alcohol dependence. Among the control group 23 had family history of alcohol dependence. There is no significant statistical difference in the family history between cases and controls. 
Figure 4 Comparison Of Family History Of Alcohol Defendence Of The Two Groups

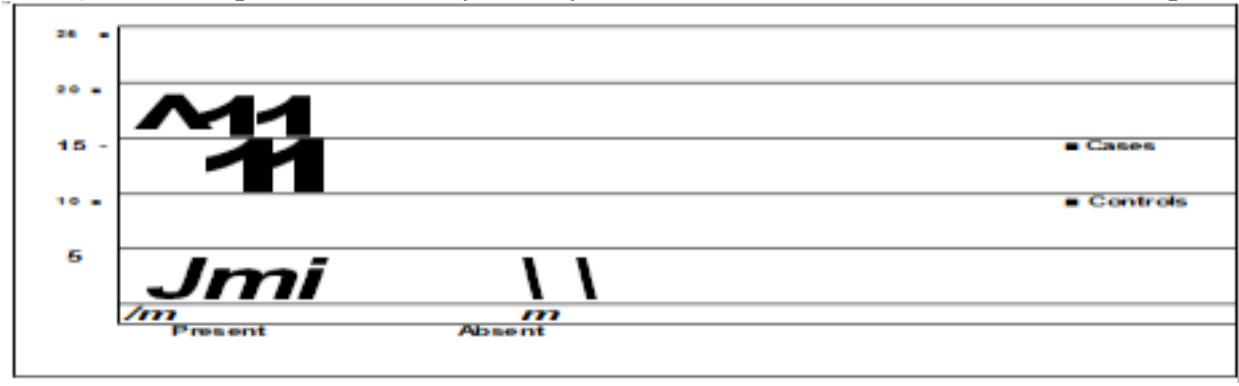

Table-5 Comparison Of Residence Of The Two Groups

\begin{tabular}{|l|c|c|c|l|}
\hline Residence & Cases & Controls & Chi-Square & p value \\
\hline Rural & 3 & 8 & 3.194 & 0.203 \\
\cline { 1 - 3 } Semi Urban & 11 & 7 & & \\
\cline { 1 - 3 } Urban & 16 & 15 & & \\
\hline
\end{tabular}

Table 5 and figure 5 compare the residence of the two groups. From the p value it is evident that there is no significant statistical difference in the residence status of two groups. However the Odds ratio of the semi urban status is $22 \%$ more than that of the controls.

Figure - $\mathbf{5}$ comparison Of Residence Of The Two Groups

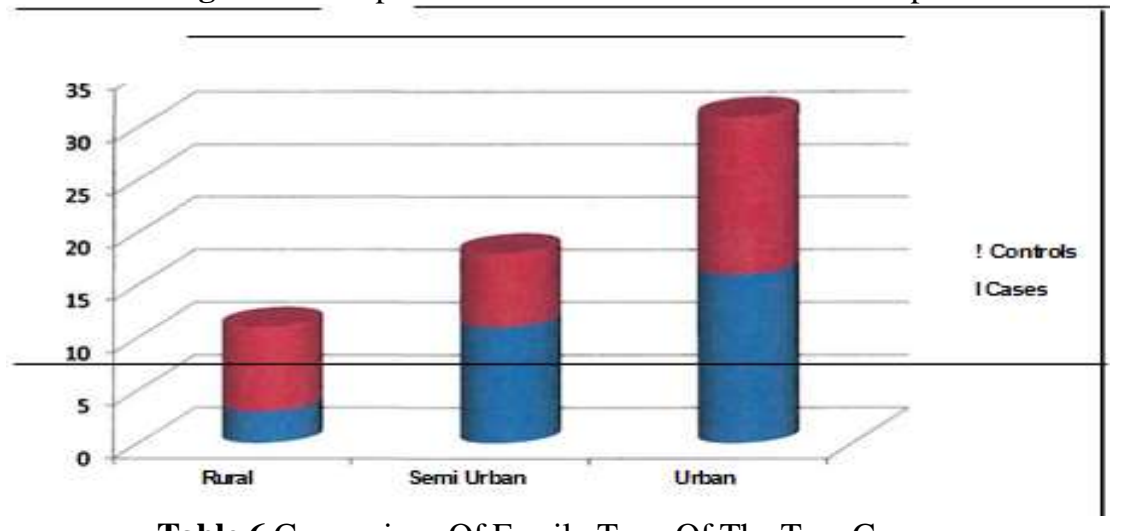

Table 6 Comparison Of Family Type Of The Two Groups

\begin{tabular}{|l|c|l|c|l|}
\hline Family Type & Cases & Controls & Chi-Square & p value \\
\hline Joint & 12 & 14 & 0.271 & 0.602 \\
\hline Nuclear & 18 & 16 & & \\
\hline
\end{tabular}

Table 6 and figure 6 compare the family type of the two groups. From the p value it is evident that there is no significant statistical difference in the family type of two groups.

Figure 6 Comparison Of Family Type Of The Two Groups

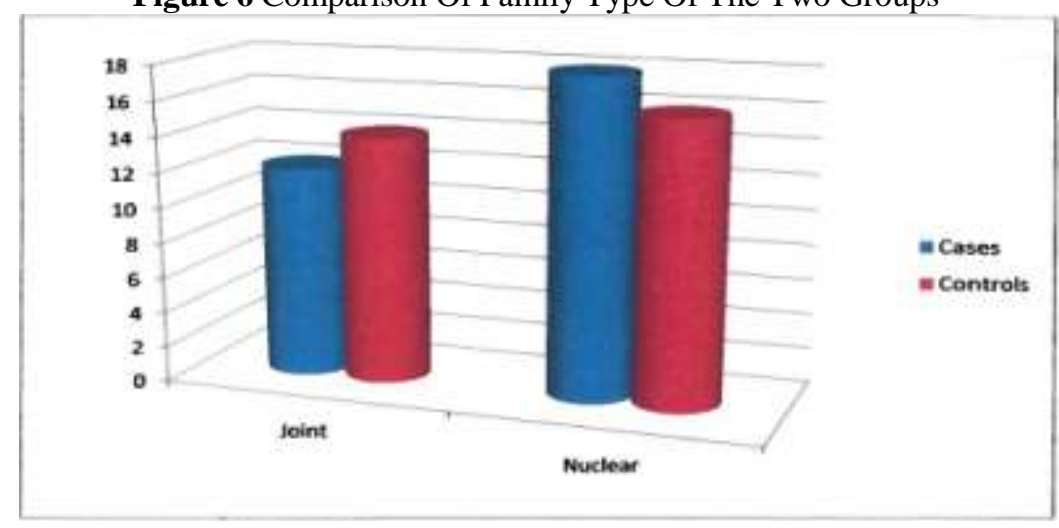


Table 7 Comparison Of Religion Of The Two Groups

\begin{tabular}{|c|c|c|c|c|}
\hline Religion & Hindu & Muslim & Christian & Others \\
\hline Cases & $\mathbf{2 9}$ & - & $\mathbf{1}$ & - \\
\hline Controls & $\mathbf{2 9}$ & - & $\mathbf{1}$ & - \\
\hline
\end{tabular}

Table 7 compares the religion type of the two groups. As evident, most of the subjects belonged to Hindu religion and there was no significant statistical difference between the two groups.

Figure 7 Mean Sten Score Comparison Of Cases And Controls Profiles On The 16 Pf Questionnaire

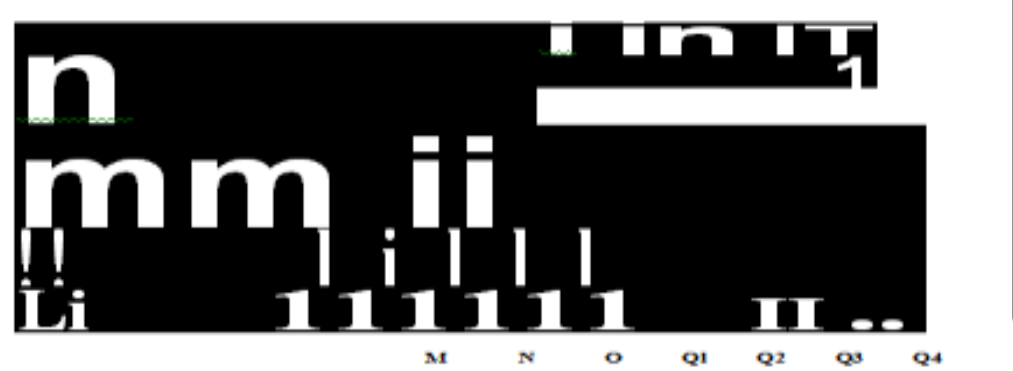

Table 8 Mean Sten Score Comparison Of Cases And Controls Profiles On The 16 Pf Questionnaire

\begin{tabular}{|c|c|c|c|}
\hline 16 PF Profile & Cases & Controls & p Value \\
\hline $\mathbf{A}$ & 4.80 & 5.63 & 0.056 \\
\hline $\mathbf{B}$ & 6.77 & 7.27 & 0.275 \\
\hline $\mathbf{C}$ & 7.63 & 7.43 & 0.639 \\
\hline $\mathbf{E}$ & 8.13 & 7.67 & 0.401 \\
\hline $\mathbf{F}$ & 7.80 & 7.40 & 0.124 \\
\hline $\mathbf{G}$ & 4.00 & 4.276 & 0.475 \\
\hline $\mathbf{H}$ & 7.20 & 6.63 & 0.154 \\
\hline $\mathbf{I}$ & 5.40 & 5.30 & 0.766 \\
\hline $\mathbf{L}$ & 7.57 & 7.53 & 0.944 \\
\hline $\mathbf{M}$ & 7.90 & 8.10 & 0.575 \\
\hline $\mathbf{N}$ & 6.60 & 5.40 & $\mathbf{0 . 0 2 0}$ \\
\hline $\mathbf{0}$ & 5.80 & 5.60 & 0.636 \\
\hline $\mathbf{Q i}$ & 7.03 & 7.17 & 0.781 \\
\hline $\mathbf{Q 2}$ & 6.37 & 5.90 & 0.329 \\
\hline $\mathbf{Q 3}$ & 6.10 & 5.60 & 0.273 \\
\hline $\mathbf{Q 4}$ & 5.80 & 5.80 & 1.00 \\
\hline
\end{tabular}

Table 8 and figure 7 show the mean sten scores of the two groups. Analysis of the mean scores indicate that the cases as a group score higher than average on 'factor N' when compared to controls.

Figure 8 Comparison Of Coping Behaviours Of The Two Groups

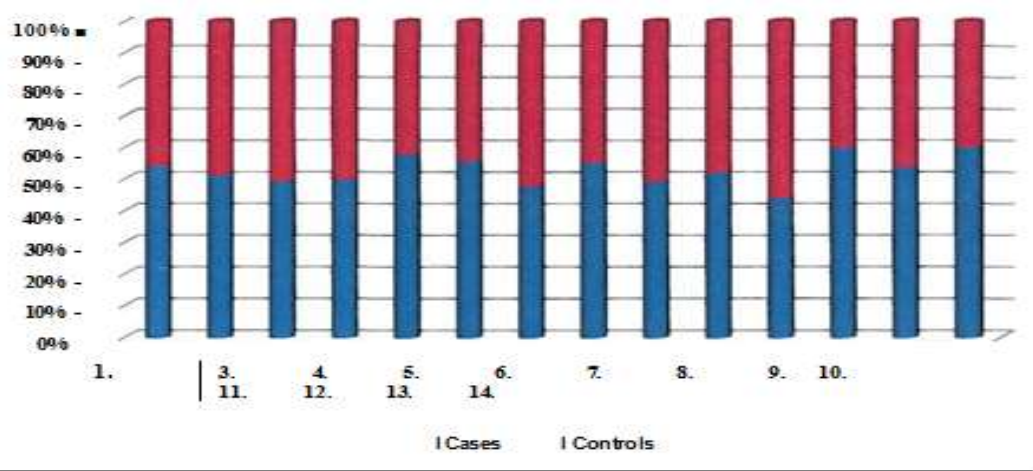


Table 9 comparison Of Coping Behaviours Of The Two Groups

\begin{tabular}{|l|c|c|c|}
\hline Coping behavior & Cases & Controls & p Value \\
\hline $\mathbf{1 .}$ & $\mathbf{5 . 4 0}$ & 4.53 & $\mathbf{0 . 0 2 3}$ \\
\hline $\mathbf{2 .}$ & $\mathbf{5 . 0 7}$ & 4.77 & 0.417 \\
\hline $\mathbf{3 .}$ & $\mathbf{4 . 4 0}$ & 4.47 & 0.872 \\
\hline $\mathbf{4 .}$ & $\mathbf{2 . 0 0}$ & 2.00 & - \\
\hline $\mathbf{5 .}$ & $\mathbf{6 . 1 3}$ & 4.43 & 0.000 \\
\hline $\mathbf{6 .}$ & $\mathbf{5 . 8 0}$ & 4.57 & 0.017 \\
\hline $\mathbf{7 .}$ & $\mathbf{2 . 8 3}$ & 3.07 & 0.471 \\
\hline $\mathbf{8 .}$ & 5.00 & 4.03 & 0.037 \\
\hline $\mathbf{9 .}$ & $\mathbf{4 . 4 3}$ & 4.53 & 0.825 \\
\hline $\mathbf{1 0 .}$ & $\mathbf{4 . 7 3}$ & 4.33 & 0.350 \\
\hline $\mathbf{1 1 .}$ & $\mathbf{2 . 4 0}$ & 3.03 & $\mathbf{0 . 0 3 4}$ \\
\hline $\mathbf{1 2 .}$ & $\mathbf{6 . 5 0}$ & 4.33 & $\mathbf{0 . 0 0 0}$ \\
\hline $\mathbf{1 3 .}$ & $\mathbf{6 . 3 0}$ & 5.40 & $\mathbf{0 . 0 3 5}$ \\
\hline $\mathbf{1 4 .}$ & $\mathbf{4 . 5 0}$ & 2.97 & $\mathbf{0 . 0 0 0}$ \\
\hline
\end{tabular}

Table 9 and figure 8 show the mean scores of the domains of coping behaviour of the two groups. Analysis of the mean scores indicate that the cases as a group score higher than average on the domains 1, 6, 8, 12,13 and 14 when compared to controls.

The controls score higher than average on domain 11 than the cases.

I.Self distraction

6. Use of emotional support $8 . \quad$ Venting

II. Humour

Acceptance

Religion

14. Self Blame 't- test' could not be computed for domain 4 as the scores were equal.

Table 10 Comparison Of Depression Scores Of The Two Groups

\begin{tabular}{|l|c|l|}
\hline Cases & Controls & $\mathbf{p}$ value \\
\hline 11.50 & 1.00 & $<0.05$ \\
\hline
\end{tabular}

Table 9 compares the mean scores on HAM-D between the two groups. Analysis shows that there is significant difference between the two groups with $\mathrm{P}$ value $<0.05$.

\section{Discussion}

This study was done with the following objectives. First to assess the personality profile of the wives of alcoholic and compare it with the wives of normal people. In the present study, the wives of alcoholics did not differ significantly from the wives of healthy people in most of the socio-demographic variables. There was no significant difference in terms of age, education, occupation, religion and family history of alcohol dependence.However these findings are not concordant with that of Bhowmick et al. ( 2001 ) (5) who pointed that codependent wives had lower social support.However there was a significant difference between the 2 groups in their residence type. The case groups were more from semi urban area when compared to the control group.In this study, the wives of alcoholics as a group deviate significant controls high scores on factor ' $\mathrm{N}$

The name of the dimension 'factor N' is low score being described as Forthright, Unpretentions, open, genuine, artless and high score as polished, socially aware, diplomatic and calculating.

Individuals who score high on factor $\mathrm{N}$ tend to be polished, experienced, and shrewd. Their approach to people and problems is usually perceptive, hard headed and efficient an unsentimental approach to situation, an approach akin to cynicism. This could be the reason for their effective coping behaviours also.

These findings are not concordant with the findings of the study by T.S.S. Rao et al. (1991) (51) which showed that there people were timid, dependent and poised. They are also not in support of the findings of the study by Suman and Nagalakshmi et al. (1993) (49) which showed that these people were more inhibited and less assertive.

This also does not support the findings of the study by Kodandaram et al. (1997) (31) which showed that the wives of alcoholics were silent, timid and group dependent. 
However there is not much of a difference between the two groups on others factors on 16 PF. This is in concordance with the findings of

T.S.S. Rao et al. (1991) (51) whose results were that the scores on $16 \mathrm{PF}$ were the same between the wives of alcoholics and healthy people.

The second objective was to compare the coping behaviors between the two groups and to study the pattern of coping behavior used by the wives of alcoholics.

The wives of the alcoholics were found to be using almost of the coping behaviours. There is a significant difference in the following domains of coping behavior between the two groups -

$\begin{array}{ll}\text { 1. } & \text { Self-distraction } \\ 2 . & \text { Use of Emotional support } \\ \text { 3. } & \text { Venting } \\ \text { 4. } & \text { Religion } \\ \text { 5. } & \text { Self-blame } \\ 6 . & \text { Acceptance }\end{array}$

Of which, 1, 2, 3, 4, 6 are considered desirable coping behaviours and 5 undesirable.This is supported by the study by James and Goldman et al. (1971) (28) who reported that they use all sorts of coping in response to the usband alcoholism.This finding is against the findings of Jones. A. Jackson et al. (1954) who stated that these people were poor copers and neurotic.Studies by Orford and Guthrie et al. (1976) (37), and T.S.S. Rao et al. 992) (43) and used a 'coping with drinking questionnaire', and shown that the commonest coping behaviour used was avoidance, discord and fearful withdrawal. But in this study it was found that the commonest coping behaviours used were use of instrumental support and acceptance, which are desirable coping behaviours. There is a significant difference between the two groups in the 'humour' style of coping behaviour which was used more by the control group, which is a desirable coping behavior.Third objective was to evaluate the presence of depression and suicidal intent in the wives of alcoholics and to compare in with the wives of non alcoholics. The study shows that there is a significant difference between the two groups on mean HAM-D scores but there is no depression in the case group.. This is against studies by Roberts and Brent et al. (1982) (39) and A. Shantala et al. (2001).Nearly $50 \%$ of the case group were employed in unskilled job and 50\% were unemployed. The study showed no depression in the case group which is supported by the study by Varghese R et al. (1998) (53) who concluded that working women experienced greater degree of psychological distress than those unemployed.Among the case group, the suicide intent was medium while there were no suicide attempters in the control group, which could be because of good social support, coping styles and personality. (The attempters in the case group however had mild depression).

There is a positive correlation between HAM-D and suicide attempters lethality which raises the need to address to the psychosocial stressors in the wives of alcoholics and screen them and include them in the treatment programmes for the husband's alcohol dependence.

\section{Summary}

This study is a care control study in which the personality profiles coping behavior and degree of depression and lethality of suicide attempt was measured in the wives of alcoholics and compared with matched controls. The wives of alcoholics did not differ from controls in most of the scores $16 \mathrm{PF}$ except in the privateness. It translates into the following deviations in the present literature. They are shrewd, socially aware and diplomatic. Most of the wives of alcoholics were from semi-urban area. The wives of alcoholics used all the coping behavior except use of substance.

They differed form the control group in using the following desirable coping behaviour more - self distraction, use of emotional support, venting acceptance and religion. They also used the undesirable coping mechanism of self blame more than the controls.

The wives of alcoholics had no depression when compared to that of controls. But difference was statistically significant. The case group had suicide attempters with medium lethality and there were nil in the control group. Hence this variable could not be compared between the two groups.

\section{Conclusion}

The personality traits deviations of the wives of alcoholics was not that significantly different when compared to that of wives of healthy controls on mean scores and proportions. However this finding may have significance on the intervention strategies in alcohol dependence. This could help in effectively using their positive attitudes. The case group was using almost all the coping behaviours, the desirable more than the undesirable. This finding implicates they are able to actively cope up with their husband's alcoholism effectively. The case group score significant difference in depression scores as compared to controls. This highlights the vulnerability of these wives of alcoholics to various psychopathology and the need to address to alcohol dependence in a family context. They also had medium lethality intent of the previous suicide 
attempts which emphasizes the need for future prevention strategies. There is a positive correlation between degree of depression and lethality of suicide attempt.

\section{Limitations}

This study was done only with female spouses of male alcoholics the male spouses of the female alcoholics was not taken up for study due to the scarcity of the samples. The study was conducted in a tertiary care hospital hence it might not be representative of the general population.Personality of the wives prior to the marriage was not assessed, hence the observed variations could not be attributed to the husband's

The severity of the alcohol dependence was not assessed which could have influenced the variables. The confounding interaction between personality, coping behavior and depression was not dealt with. The association between the variations in the variables and the outcome of the husband's alcoholism was not considered.

\section{Future Directions}

Studies with large sample size randomly drawn from the community representative of both the sexes are required to validate or disapprove the above findings. More prospective studies are needed to study the association between the husbands alcohol dependence and its effects on the wives' personality. There is a need for more research and application to clinical practice as far as the psychopathology of wives of alcoholics in response to the husbands' alcohol dependence is concerned.

\section{Bibliography}

[1]. 1.^A. Shantala, M.M. George, J.Henry and V. Benegal Bangalore (2001). Stress, morbidity and copying in spouses of alcoholics, Indian Journal Psychiatry, Vol: 43, 43-44.

[2]. 2. v Asher, Ramona and Brissett, Dennis (1 988). Codependency : A review from women

[3]. married to alcoholics, International Journal of the Addictions, Vol. 23 (4), 33 1-350.

[4]. Avila, Escribano J. J. and Ledesma, Jimeno, A. (1990). Actas Luso Espanolas de Nedogia Psiquiatna, Y Ciencias Afifines, Nov. - Dec. Vol. 18 (6), 355-363.

[5]. BeckAT, Schuyler D, Herman I: Development of suicidal Intent Scale in the prediction of suicide Bowie, Maryland : Charles Press 1974,45-56.

[6. Berger, G. (1993), Alcoholism and the family. New York: Franklin Watts Finney, J.,

Moos, R., Cronkite, R. \& Gamble, W. 1983, 'A conceptual model of the functioning of married persons with impaired partners: Spouses of alcoholic patients', Journal of Marriage and the Family, vol. 45, pp. 23-34

[7]. v Bhowmik. P, Tripathi. B, Jinghan. H \& Pandey R (2001). Social Support, Coping

[8]. Resources and Codependence in Spouses of Individuals with Alcohol and Drug Dependence. Indian Journal of Psychiatry. 43(3). Pp: 219-224

[9]. British Journal of psychiatry 139:391-396 (1981). The predictive validation of a suicide intent scale : a five year followup.

[10]. Carver, C.S. (1997). You want to measure coping by your protocol is too long: consider the brief cope: Internation Journal of Behavioural Medicine, vol. 4(1), 92-100.

[11]. Carver, C.S., Scheier, M.F., Weimtraub, J.K. (1989). Assessing copying strategies : A theoretically based approach. Journal of personality and social psychology, vol. 56, 276-283.

[12]. Mo. Catell RB, Eber HW, Ttatsuoka MM, eds Handbook for the 16PF questionnaire : Institute for personality and obesity testing, (1970); 83-283.

[13]. Catell, R.B. (1980). Personality theory derived from quantitative experiment.In: Comprehensive Text Book of Psychiatry.Ill Ed., (Eds) Harold, I.Kaplan, Freed Man, A.M. and Sadock, B.J. London : Battinore, Willams and Wilkins.

[14]. Chandrasekaran .R \& Chitraleka. V (1998). Patterns and Determinants of Coping Behavior of Wives of Alcoholics. Indian Journal of Psychiatry. 40(1). Pp: 30-34o

[15]. Cheek, F. F.; Franks, C. M; Laucins, J. and Burtle, V. (1971). Behaviour modification training for wives of alcoholics, Quarterly Journal of Studies on Alcohol, 32,456-46 1.

[16]. Crisp, B. R. and Barber, J. G. (1 995). The Drinker's Partner Distress Scale: an instrument for measuring the distress causal by drinkers to their partners, International Journal of Addiction, June, 30(8), 1009-1017.

[17]. Edwards, Patricia; Harvey, Cheryl and Whitehead Panic (1 973). Wives of Alcoholics: A critical review and analysis, Quarterly Journal of Studies on Alcohol, March, Vol.34 (1), 112-132.

[18]. Family interventions in the treatment of alcohol and drug problems. Drug and Alcohol Review, 24, 369- 385.

[19]. Futterman (1953). Personality trends in Wives of Alcoholics, Journal of Psychiatric Social Work, 23,3 7 - 41

[20]. Roberts, L.J., \& Leonard, K.E. (1998). An empirical typology of stress and copying in wives of alcoholics.

[21]. Rothberg, N.M. 1986, 'The alcoholic spouse and the dynamics of co-dependency ${ }^{1}$, Alcoholism Treatment Quarterly, vol. 3, no. 1, pp. 73-86.

[22]. Rotunda, R. J., \& Doman, K. (2001). Partner enabling of substance use disorders: Critical review and future directions. Family Therapy, 13, 259- 274. 
[23]. Sangy, D. de. (1 964). Personality patterns of wives of alcoholics, Quarterly Journal of Studies on Alcohol, 19,322

[24]. Sathyanarayana Rao and Kuruvilla (1992). Study on the coping behaviour of wives of alcoholics, Man Journal of Psychiatry, $125,433-441$.

[25]. Schaef, A.W. 1986, Co-Dependence: Missunderstood and Misstreated, Harper \& Row, San Francisco.

[26]. Silverstein, H. (1990), Alcoholism. New York: Franklin Watts Kalashian, M.M. 1959,

'Working with the wives of alcoholics in an outpatient clinic setting ${ }^{1}$, Marriage and Family, vol. 21, pp. 130-3.

[27]. Snaith RP, "Present Use of the Hamilton Depression Rating Scale: Observation on Method of Assessment in Research of Depressive Disorders, "By J Psychiatry, 1996, 168(5): 594-7.

[28]. Sreedevi. M, Gangadhariah H.M \& Benegal V (2001). Domestic Violence, Stress and Coping in Spouses of Alcoholics. Indian Journal of Psychiatry. Vol 43 (supplement).

[29]. Steinglass, P. (1975). Experimenting with family treatment approaches to alcoholism. 1950-197 5 - A Review, family Process, 15 (1), 97-123.

[30]. Suman, L. N. and Nagalh, S. V. (1 993). Personality dimensions of alcohol dependent individuals and their spouses, N M A N S Journal, July, $11(2), 95-98$.

[31]. Tomelleri, C. J; Hqanic, M; Herjanic, B.L. and Wetzel, R. D. (1 977). The wife of the alcoholics. In. Currents in Alcoholism (Eds.), Frank. A. Seixaz. Vol.4. 29-37, New

York, Grune and Stratton. 51y T.S. Sathyanarayana Rao, K Kuruvilla (1991). A study on the personality characteristics of wives of alcoholics, Indian Journal of Psychiatry, Vol:33, 180-186.

[32]. Tyler, D. J. and Schaffer (1979). Degree of Sobriety in male alcoholics and coping styles used by their wives, British Journal of Psychiatry, 135,43 1-437.

[33]. Varghese R (1998). Psychological distress, social disability and coping among wives of alcoholics. NIMHANS Journal, 16(2): 148

[34]. Wallen, T. (1953). Wives of alcoholics: 4 trpes observed in a family serve agency, Quarterly Journal of Studies on Alcohol, $14,632$.

[35]. Wekesser, C. (1994), Alcoholism. San Diego: Greenhaven Press, Inc.Mendenhall, W. 1989, 'Co-dependency definitions and dynamics', Alcoholism Treatment Quarterly, vol. 6, no. 1,pp. 3-17.

[36]. 56. Wiseman, J. (1991). The other half: Wives of alcoholic and their social-psychological' situation. New York: Aldine de Gruyter.

6) Occupational Status

\section{Appendix -1socio - Demographic Data}

7) Income (per month)

8) Religion

9) Current Residence

10) Type of Family

11) Family History of

Alcohol use

Married (1) Primary (1) Degree (3) Unemployed (1) Skilled (3)

Separated (2) Higher Secondary (2) Professional (4) Unskilled (2) Professional (4) Rs. 1000-5000 (2),

"sa\}(jpbqc0
u5ofi
6I65I65I

1516111(o69I (gnSlffiaillffiUUL-LUl? @n5lu5li_(Bail@ Qg,iflj5gj
Appendix - 2

fftfliurrsn"

jg Q 6I6ifIf) 


\begin{tabular}{|c|c|c|c|}
\hline 1. & & & $\begin{array}{l}\text { Qffiijlffirtijr6ia6ff)Ni Ffrfl } Q^{\wedge} \text { ILJUJ } \\
\text { A ^^Ffl5!Fe-L/Rlleisr/Rr? }\end{array}$ \\
\hline 2. & 7-Ii> 1/2 6I6JFU5J 3-Ffi@ & & 5-A@ Q $\{5$ (R5*Ffiidfi? \\
\hline 3. & $\begin{array}{l}0 \text { a \$L.Llflllljigt(8lu } \\
\text { [Blffiffi } \\
\text { (?GU6ffifi(5qud6ffi£Ii } \\
\text { 6iugurrg]Ib } \\
\end{array}$ & $(* 0$ & 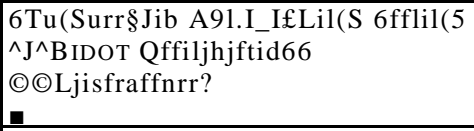 \\
\hline 4. & $\begin{array}{l}\text { Uffsidffi!/ Qunuisouju } \\
\text { L|SJ)6^Ib Gurrgjii) Qpffitb } \\
\text { Ai6!Fri Rrid6o }\end{array}$ & \begin{tabular}{|l|l}
$(\ll)$ \\
\end{tabular} & $\begin{array}{l}\text { Ctaffirr6oa5siub ^ }{ }^{\wedge} 6 \text { iisurrpi } \\
\text { Qffu!Nurrid60 R, } \\
\text { @(!5Uu*Rrffi6nrt? }\end{array}$ \\
\hline 5. & $\begin{array}{l}\text { J56toffiullu(36>J6trotfd6rofdu } \\
\text { ®Liff } \quad \mathrm{J}^{\wedge}[\mathrm{T} \\
\end{array}$ & & ^OIbuidrriltarjrr? \\
\hline 6. & $\begin{array}{l}\text { Qfflullju) } \quad \text { \&6wttfLjurt6bi } \\
\text { Guit6U[8กUn7 }\end{array}$ & & 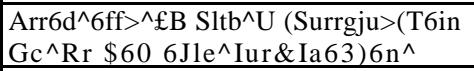 \\
\hline 7. & $\begin{array}{l}\& \text { QP\& }>\quad \text { 6isl619uj(Blffi6lfl6V) } \\
J^{\wedge} \mathrm{Fr} \quad \mathrm{J} \& 6060 \\
\text { (Jp6b)Pu516b } \\
\text { (Sa6rrfbptD6iflLjueij[Rrt? }\end{array}$ & $(\ll 0$ & $\begin{array}{llll}\text { (Ouffrtudffd } & 61 I L^{\wedge} & 615160 £ \S L & \text { Clldsnbbtu)Rrffi } \\
\text { @Girbj@Rf }\{\text { Rrr? } & & \end{array}$ \\
\hline 8. & $\begin{array}{l}\text { Jgfr ^Fir @6i5luj]Rft\& } \\
\text { 6fl(J5ibljrfrrn"? }\end{array}$ & $(\ll 0$ & $\begin{array}{l}\text { @Luj5^1rj (O6u6ff)6V) } \quad \text { Qflfujlij } \\
\text { Eflcfbibqrfr/Rr }\end{array}$ \\
\hline
\end{tabular}

\begin{tabular}{|c|c|c|c|}
\hline 9. & $\begin{array}{l}\text { 6i6urr \&-Jsnmg)GS)B }) \\
\text { A_2 } \mathrm{u}^{\wedge} \mathrm{Gj6ij \S J} \\
\text { Qurr(!5j5flyidrni3(Nja(5(8idr } \\
\mathrm{r} \\
\text { ^Hjuljluul-Leuit Ufbffflffi } \\
\text { Ahnfenicujiren } \\
\text { (Lp65)\{Du51so @^^La } \\
\text { Ffirliarfnrrr? }\end{array}$ & ${ }^{*} \mathbf{*}$ & $\begin{array}{l}\text {,£16ijftjrrnrii } \mathrm{R}^{\wedge} \mathrm{Fr} \mathrm{O}^{\wedge} \text { Iiiujseij } \\
\text { Idmliaprr? }\end{array}$ \\
\hline 10. & $\begin{array}{l}\text { @(J5 } \\
\text { 6^L6idi_Ujrrl.(5ffi6iflg2jii) }\end{array}$ & $(\ll 0$ & Ffgijtaiaib 6islg5)L.Ujit(S6^!Jrr? \\
\hline 11 & $\begin{array}{l}\text { Rsfr Lj(5^^6iju6ffi } \\
\text { 2_(Tiii\&Jf16)(3fisrnt? }\end{array}$ & $<0$ & $\begin{array}{l}\text { 2_6ui§J ^P6w6iru5)So } \\
\text { Rfljb^65)65iujrrllrbis6fr ^ } I^{\wedge} S \\
\text { Qffift6iot(Bi_@(T5S(\$Idrr? } \\
\text { "-- }\end{array}$ \\
\hline 12. & $\begin{array}{l}\text { A_Ii)6ididu Urdffiksuj Rgrr } \\
\text { Eu((5[B^|6ija5fj }) \ll R r 65 t \\
\text { Ffjb^Rruurajasrr } \\
\text { 9fdu@61JSJ6D5ll-Rt? }\end{array}$ & & $\begin{array}{l}\wedge \text { 6il6uftf)J 2_L0£B }(\mathrm{G} \quad \text { P§Llp61js^ } \\
\therefore .{ }^{\circ} \text { @ 6065>50lufi? }\end{array}$ \\
\hline 13. & $\begin{array}{l}\text { Eurrifl 6ujpnua Ng1r/Icuff } \\
\text { Qff6O6u^6w«5u } \\
\text { Qujbjj51(Nf,Ui3(R(Ruj16in } \\
\wedge !, 5 \text { mliffrflaqffi65ig)I } \\
\text { Gi!PnfJffit(Fj6\%Rr? }\end{array}$ & & $\begin{array}{l}\text { A } \\
\text { Qffijj§J6i3(B6iirrrr? } \\
<G\end{array}$ \\
\hline 14. & $\begin{array}{l}\text { @Pru516^KS6Orr } \\
\text { U6n)6i^L(S6O(T } \\
\text { Q£F6o6s>Au5|Gi) T^Fy } \\
\text { Gg65i65ieb 6U|^1(SUJ } \\
\text { Q6iisifi(2itj (Seu^^Ffi6ida } \\
\text { Urrfrullorrr? }\end{array}$ & & $\begin{array}{l}\text { I51ijilirr65rfrlffi6iflllb Surflu Qurr(Ipgj } \\
\text { Gurtffi@6i!Rrrr? }\end{array}$ \\
\hline
\end{tabular}

\begin{tabular}{|c|c|c|}
\hline 15. & 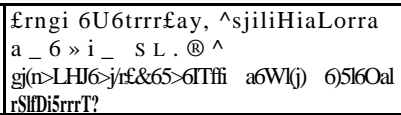 & $\begin{array}{l}\text { ^)eu63)5ruuff)p51^^ } \mathrm{Q}^{\wedge} \text { ifljsaj QaiTCTrsn ^.rrGiJib } \\
\text { Qan6fr6i!rrrr? }\end{array}$ \\
\hline 16 & CTaiClJgpllb $2-\mathrm{bl} 5 \& \mathrm{~A}$ & $\begin{array}{l}\text { QarTtg^aF CrBrrii)^^jgj a_u>6B)ii> } \\
-2=2 \mathrm{U}^{\wedge} \text { ffi-Qarr€OTrGt—@ (j5a@ionF? }\end{array}$ \\
\hline 17 & $\begin{array}{l}\text { @ fr <@jg2i6ijfioasif£l6b n?fr } \\
\text { iDffiffi6»sir» arrsRiT } \\
\text { 6i5)(ri)ibq«ffrrr? }\end{array}$ & $\begin{array}{lll}\text { 6filL(5L) } & \text { ISIGfT61D6na6iOGIT } & \text { 61J69)priU }\end{array}$ \\
\hline
\end{tabular}


A Study of Female Spouses of Male Alcohol Dependence Patients - case control study

\begin{tabular}{|c|c|c|c|}
\hline 18 & $\begin{array}{l}\text { 3,5,7,9", 6T65tguii) } \\
\text { CT6tnfra(gTj)ffi@Li dig)@ } 11 \\
\text { euorflfD^^rT? }\end{array}$ & & $10 \mathrm{eu}^{\wedge} \mathrm{alp} \wedge \mathrm{rr} ?$ \\
\hline 19 & $\begin{array}{l}\text { a_u>aj (Suffooffu iSfofr } \\
\text { QffsiS fFrruJassr^ (Surrg] } \\
\text { QurrnjeiDiD }\end{array}$ & & $\begin{array}{l}\text { ^J06B)65ILJ Ujbnfil } \quad \text { a6U65)60U } \\
\text { jg((JT)Ui5firffi6TTrr? }\end{array}$ \\
\hline 20 & 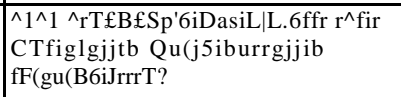 & $\begin{array}{l}C \\
<\end{array}$ & 6U(r56u§j 6urjil(BQu)OTp ^irfilaSrrnr? \\
\hline 21 & $\begin{array}{l}\text { UMT61f)6OU QUtt(1§GS)ff, } \\
\text { €5L^^ei) } \\
\text { ^jLrBjaSla e9i_j55Ui9L }\end{array}$ & & a6i51uy,L.(3ii) ej6O6)516iDi_a a^ludgnr? \\
\hline 22 & $\begin{array}{l}\text { u>sa }(\text { S ]5£B @ } 5 \text { gjsnuib } 0(510 \\
\text { QfFfiffiieiDsoff Qffrr6O6orriD6O i^rr } \\
\text { 56flui3fT«6Tin"? }\end{array}$ & & \\
\hline 23 & IBL^figl 6i51(Bsi!\{rn"? & & $\begin{array}{l}\text { S6iiQrDrT([56ijiT Q^fiLiBjal 6ro6iiaailL_ir) 6T6inn]j } \\
\text { arT0\$@uisgrrr? }\end{array}$ \\
\hline 24. & $\begin{array}{l}\text { @ajj5^liT }{ }^{\wedge \wedge} \text { (6ffi a_njjuqffi6iD6nLj } \\
\text { Oarr6fre)!rirr? }\end{array}$ & $(\%$ & ix>aa6fr §,ip 655jbn51@f5SI (Surfl^ £frui5rj-rr? \\
\hline 25. & $\begin{array}{l}\text { a5iB)\&sD6JT } \\
\text { a_2Ji0fj(SiDUJfTsinn"sJ|LD } \\
\text { Qu(j5ibufr6Orrffln ice\&e66fr } \\
\text { 2L_65I6iDID6»UJ0«5rr6lfr } \\
\text { 2J_B)_T6\&a[5T6\&CIf G6)flg)J } \mathbf{r}^{\wedge}[\mathrm{T}\end{array}$ & & $\begin{array}{l}\text { if>aa6n iDrbrD6unra6)Den 2_2110S5rr6i51ilL_a5rr6O } \\
\text { ^eii6U(Tg)] 2_6tDrruumTa6fr 6i6in rg)6W65iui5grT? }\end{array}$ \\
\hline 26. & $\begin{array}{l}\text { ffi(B6ff)iDiurra 2_sB)y)\&\& } \\
\text { 661J6WII^UJ } \\
\text { C6U6»60U51(\{5ffSiDail5IS0 } \\
\text { Qu@iDurr6Onr6Bi6ijrra6nr } \\
\text { CTg^gja Qarr6fr(gijib } \\
\text { 9iiisi51gjjib 5ft@s36onr6sr } \\
\text { @iiJ6ff }) 6 i j \text { r^fr } \\
\text { 6T(B^§jaQ«rr6frffISprr? }\end{array}$ & $(\ll 0$ & $\begin{array}{l}\text { ID(i)fDITa6iD6IT 6ISII__@65)fI)6U(Ta } \\
\text { erg^gja QanCTr6iJrjTr? }\end{array}$ \\
\hline 27. & $\begin{array}{l}\text { «j65>68T0ajib a^ibua } \\
\text { ajiLLrrala ali_uu6ij>0 o } \\
\text { ffLo(T6i5l£gja Qarrcnrfjrr? }\end{array}$ & & a_ir>a@ Q0rrj5^1rran6U s_6wr(5 uanfrgLDrr? \\
\hline 28. & $\begin{array}{l}\text { (8urrf\$hiJ arrrr66sitb } \\
\text { g§ILi5!6O6orrfl9@aa ^uiTUjib } \\
\text { a r } r^{\wedge} \text { a } Q^{\wedge} \text { a a lpaj e ia n p } \\
\text { CTuGurrajib j^iif ^®arfijrr? }\end{array}$ & & $\wedge$ jeiisurrgji rgrr^$\wedge^{\wedge} \odot £ F$ iDUilifipriT? \\
\hline 29. & 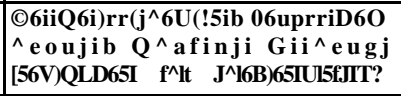 & & $\begin{array}{lccc}\text { «1§J } & \text { I£lfl\& } \\
\text { n§)6tD65Tui5rrrr? }\end{array}$ \\
\hline
\end{tabular}

பெறும்பாலும் நீர்

பொறாமையுண்ர்ச்சி

கொள்வதில்லையா?

\section{j56eoiuiTa>6ii 6i6ooi6injiifBi(DrrntB6jiiT / \\ 5L.6)0I_UJIT6Sin]69IIT£B6X|tb \\ )$($ g>S6!B6Tr IDffif\&CTI \\ fl J(Tffie6 \\ IU(ButT§Jlb}

\begin{tabular}{|c|c|c|c|}
\hline & 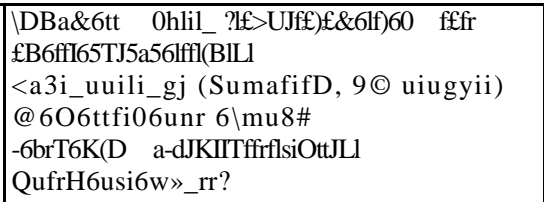 & & j56Og2J6irairrffrfl Qugl|6i5rrrr? \\
\hline 45. & 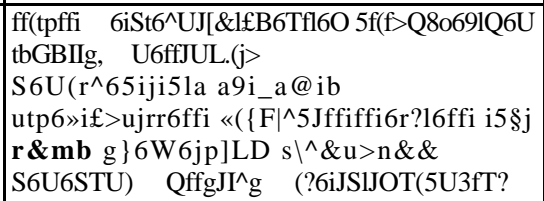 & $\mathbf{a}(\mathrm{i} \ll)$ & $\begin{array}{l}\text { CtprbnS1Qjjib jB6iS65i (ip6»rD i\&y } \\
\text { rgl£5rT6ffi } \\
\text { G»61]6Wl(F)I>rT? }\end{array}$ \\
\hline
\end{tabular}


A Study of Female Spouses of Male Alcohol Dependence Patients - case control study

\begin{tabular}{|c|c|c|c|}
\hline 46. & $\begin{array}{l}\text { 6JQ5 IDSfl\&L (g(ip6lffl6inifl6ff)L_(SUJ } \\
\text { CTuCurrgjib j^fr a6)5)uL|i_6iri } \\
\text { ffi6O^^gip6urr(B65 }\{\text { rrr? }\end{array}$ & $(\ll 0$ & $\begin{array}{l}\text { 2_LDffi@ Q51(|5LJU(lpeiT6TIUt9 } \\
\text { a_iiiu616i9i_^gjffi@ J5i_ui5rrrr? }\end{array}$ \\
\hline 47. &.$^{\wedge}$ liaQpsnp @ $\S$ lssi $\mathrm{c}^{\wedge}$ lfBeifirn"? & $(\ll 0$ & $\mid \operatorname{rgl}^{\wedge}$ rreffiuwT\&ff rflj5flg|^|^Qa56rf)6i!jriT? \\
\hline 48. & $\begin{array}{l}\text { ^irf)u 6iS16i9Uj^^§jffi@ii) r£rr } \\
\wedge \text { J6rr6ij ufiffilffi a6U6B)6OU uQrfrrrr? }\end{array}$ & & $\begin{array}{l}\text { ^§y «@juui9Qujnr6)ngiJii> Quifliu } \\
\text { 151(Ja\#\#l6iD65TUJrT£BG6U } \\
\text { Ge6rT6ihfTij6xi^1606io60ujrr? }\end{array}$ \\
\hline 49. & $\begin{array}{l}\text { £BfT(j)S6ifli>£16TT6Tr U)pT\&ie\&65)6TrU } \\
\text { u (rsiffimju^16 \{ ) rgfr tSjafse wn ) } \\
\text { QffQ2jgia\}j6>frr.rT? }\end{array}$ & & $\begin{array}{l}\text { U6fr6rf1aS160 wn6sjn6uh\&(gr^a@ um_u> } \\
\text { Gurr^lULSgiT? }\end{array}$ \\
\hline 50. & $\begin{array}{l}\text { 'Qffinr^ffii)' } \quad \text { 6T65iu§j L0<BB. } \\
\text { Q1D6f)6 } \backslash \text { SllIJg] } \quad \text { 6T6if[p } \\
\text { Qurr(i56nu^Bu)rr? }\end{array}$ & & $\begin{array}{l}\text { 'LfilflBff \#ln51UJSj' 6T65I21I } \\
\text { QufT([56iTU(5UDIT? }\end{array}$ \\
\hline 51. & 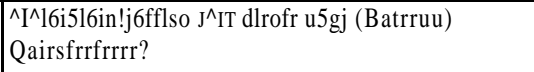 & & rf)airr6\&TiDrr« GsfTuib Qarrerreil^ rr? \\
\hline 52. & $\begin{array}{l}\text { SL-IDfiB® 6UL^IlU6O LJiflU6UQ3ia(5 } \\
\text { CiDgjjii) a_u^^)fT6!fiir» } \\
\text { 615l6n6TTUU^lgilLb, 2_6TI6Tr IDL.I96V) } \\
\text { (BurrgiLDrrffiffla Qffitr6n66uiT(8u) } \\
\text { 6T6Jrm t^nr «SIL(Ba Q\&nQulSljn? }\end{array}$ & $(4 \mathrm{M})$ & $\begin{array}{l}\text { ail(5UU(S61J§|ld ^J6U(J565)I_UJ } \\
\text { a5i_6JDip^rr(o6w 6T60Ts ffi(j5\$|65S(jrir? }\end{array}$ \\
\hline 53. & $\begin{array}{l}\text { Qu(j5iburr60tT6iti Qurr(ip^l6i) } \mathrm{r}^{\wedge} \mathrm{fr} \\
£\left(n j^{\wedge} \text { SjjT6OTr£)a asnni5iULli_6iffl@LLii3(jiT? }\right.\end{array}$ & $(\ll)$ & $\begin{array}{l}\text { Qu(j5ii)urTg2iub @6^1ujnfffi6ijub rflifl^gia } \\
\text { Qarr65jfr(3Lb@oudfraenrr? }\end{array}$ \\
\hline 54. & $\begin{array}{l}\text { ^rflf\&iati)rT65i 6)5^1s6jnsnLJ urorfil } 0 \\
95 \mathrm{~J} U>\text { Qu i r } \odot 6 \mathrm{nu}(\mathrm{g} \wedge \wedge \text { IDfrilifitrrr? }\end{array}$ & & $\begin{array}{l}\text { ^6iD61J SL_UDffi@ } \quad « \text { SJ(!561J@UL) } \\
\text { EffllLg1DfT? }\end{array}$ \\
\hline 55. & $\begin{array}{l}\text { jgrr auj(Su>a_6»\{f»aa C6U65Jii9miJ } \\
\text { G6vi6S)6O69)aj CTrrja 6iSI@ii >Lja5orfT? }\end{array}$ & & $\begin{array}{l}\text { @(f561JCIDIJUJ(5^a5 UDji)Q\{DfT@61J6ro\{r } \\
\text { ffjBfig1^gia Qarr6wn(gi_u51(i5a@ii) }\end{array}$ \\
\hline 56. & $\begin{array}{l}\text { U6fr6itl ^ j,rfliflujfrrru51(jT, aa6 } \mathrm{r}^{\wedge} \mathrm{fr} \\
\text { 61516I0ip655(jrT }\end{array}$ & & $\begin{array}{l}\text { Qurfluj C6UL.6B >L_«ttiTrr6i(iiras «5l(i5 } \\
\text { iDLinSiirr? }\end{array}$ \\
\hline
\end{tabular}

f)6!r>UJ QfflUUJ6i5l6\{)6i060UJIT6iniT6\{), a.sror6<iu>uSl6n65r

\section{Informed consent proforma for Subjects :}

\section{Informed Consent forms}

As you are aware, your husband has been receiving treatment for a psychiatric condition called alcohol dependence. As you know alcohol dependence in men affects not only the health of the person consuming it but also the family members in many ways. It also causes a range of psychiatric disorders in the female spouses. In this study we are investigating certain aspects of your mental health through certain questionnaires. We shall assess your personality profile, coping behavior, the presence of depression and suicide intent in you. We compare it with female spouses of healthy volunteers. We seek your consent to take part in this study. If you consent, we will examine your functioning and symptoms by interviewing you in detail. This will involve answering a few questions in a structured format. These tests will take about 2 hours to complete. We will show you how these tests are done before starting assessment. After understanding the nature of the assessments, if you choose not to undergo the tests, your decision will be respected by us. Taking part in this study does not involve any risks to your health. Please be informed that you have every right to refuse to take part in this study at any point in time. Your refusal to take part in the study will not adversely affect your husband's treatment in any way.

\section{Undertaking by the investigator :}

Your consent to participate in the above study is sought. You have the right to refuse consent or withdraw the same during any part of the study without giving any reason. In such an event, your husband will still receive best possible treatment, without any prejudice I / We undertake to maintain complete confidentiality regarding the information obtained from the subject / patient during the course of the study. The information obtained from you will be used for this research only. If you have any doubts about the study, please feel free to clarify the same. Even during the study, you are free to contact any of the investigators for clarification if you so desire. The list of investigators and their phone numbers is given below : 1. Dr. Shanthi, MD., Post graduate (Psychiatry), JMH, Tel : 9962588343. 2. Shanmugiah, Associate Professor of Psychiatry, IMH, Tel: 9443970057 . Consent:

I have been informed about the procedures of the study. The possible risks too have been explained to me / us as stated in the information. I have understood that I have the right to refuse my consent or withdraw it any time during the study without adversely affecting my husband's treatment. I am aware that by subjecting to this investigation, I will have to give more time for assessments by the investigating team and that these assessments do not interfere with the benefits. 
I, …….................................................... the undersigned, give my consent to be a participant of this investigation/ study program / clinical trial.

Signature of the Subject (Name and Address)

Signature of the husband

Signature of the Witness (Name and Address)

Signature of the Doctor I Investigator

Name and Designation

Date :

Place: 